\title{
Gravity Based Energy Storage System: A technological review
}

\author{
Dr. Ravi Gupta ${ }^{1}$, Preet Lata $^{2}$, Arpit Gupta ${ }^{3}$ \\ ${ }^{1}$ Assistant Professor, Engineering College Bharatpur, Rajasthan, India, raviguptabtp@ gmail.com \\ ${ }^{2}$ Assistant Professor, Engineering College Bharatpur, Rajasthan, India, preetklata@gmail.com \\ ${ }^{3}$ Student, Electrical Engineering Department, arpitg2208@ gmail.com
}

\begin{abstract}
As in today's world the penetration of renewable energy resources is increasing for electricity production, the problems due to unpredictable nature and variable output of these resources increases. Solution to these problem leads to the need of proper energy storage systems. There are various energy storage techniques that been developed and being using since long time e.g. battery storage, compressed air energy storage, pumped hydro storage, flywheel storage etc., but each technique has some limitations. This paper explores and gives an overview of recent gravity based energy storage techniques. This storage technique provides a pollution free, economical, long lifespan (over 40 years) and better round- trip efficiency of about 7585\% (depending upon technology used) and a solution for high capacity energy storage. Through this study it has been shown that this storage system has very high potential and can be used widely in future to store the renewable energy to overcome the problem of stabilization the electric grid.
\end{abstract}

Key words:Energy storage, Gravitational potential energy, Grid balancing, Off-peak and peak demands, Regenerative braking.

\section{INTRODUCTION}

Limited availability of fossil fuels and pollution due to conventional energy production leads the world to think some carbon free, clean and pollution free sources as an alternate of energy resources. Renewable energy sources (RES) like Hydro, Solar, Wind, Tidal, Geothermal, Biomass etc. have provided pollution free alternate to produce electrical energy. Recent advancement and technological improvement has also increased the use and reliability of RES for electricity production and thus installation of these sources is increasing worldwide[1]-[3]. Figure 1 shows data provided by International Renewable Energy Agency (IRENA), the total worldwide renewable energy generation capacity was $2537 \mathrm{GW}$ (at the end of 2019), Which was $7.4 \%$ (176 GW) more than the last year generation capacity. Hydro power had the largest share of $47 \%$ of total generation capacity among all other RES followed by Wind power (25\%) and Solar power $(23 \%)$. Year by year the total installed capacity of RES technologies is increasing. In the year 2019, globally the solar power capacity is increased by $98 \mathrm{GW}$ followed by Wind ( $59 \mathrm{GW})$ and Hydro power (12 GW) [4]. Contribution of other renewable resources like geothermal, tidal, biomass is comparatively low, so this paper focuses mainly on solar, wind and hydro power.

Now, as the share of RES is increasing in the electricity generation the problem associated with its storage also gaining more attention. This problem arises due to the unpredictable nature of these resources. Renewables, such as wind and solar, are much less flexible than fossil fuels due to their variable, intermittent and to some degree unpredictable nature .So till now various studies and technological developments have done for developing various energy storage solutions like battery, flywheel, compressed air, pumped hydro storage, chemical storage, electromagnetic energy storage, electrostatic energy storage, thermal storage, gravity battery storage [1],[3],[5].

Major contributor in energy storage i.e. Pumped Hydro Storage (PHS) also has geographical limitations, much larger land requirement and higher initial cost. Similarly batteries like Lead-Acid battery, Lithium-ion battery, Nickel-Cadmium (NiCd) etc. suffers from limitations like high storage 
cost, short life time, heavy weight and high internal impedance [3].

So, as a new kind of energy storage technology, gravity energy storage system (GESS) emerges as a more reliable and better performance system. GESS has high energy storage potential and can be seen as the need of future for storing energy.

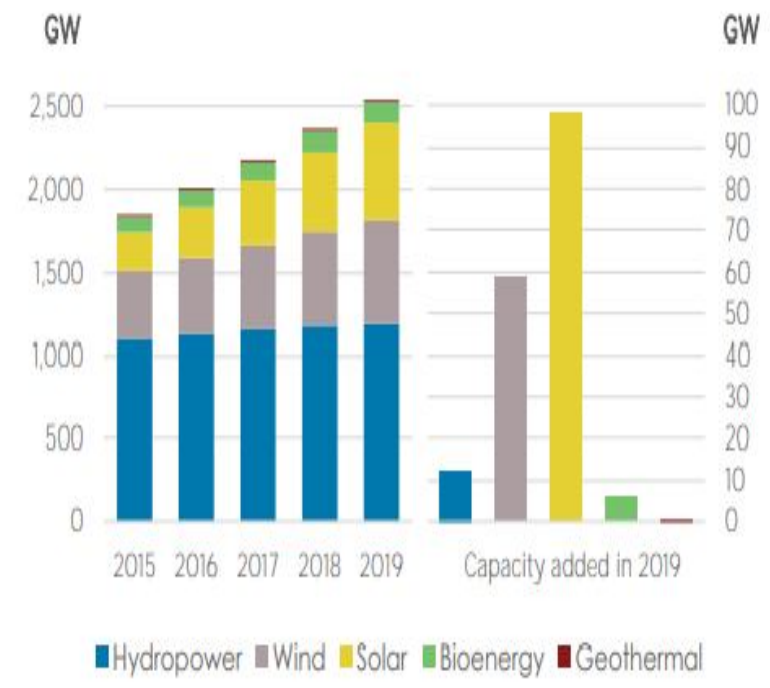

Figure 1:Renewable power capacity growth [4].

However, GESS is still in its initial stage. There are very few example of its practical implementation, so further study and improvements is needed so that full potential of GESS can be assessed and it can be used as a better alternative for energy storage solutions. PHS is also a type of GESS but it has some limitations as discussed earlier. Recent GESS is about gravity based rail energy storage, vertical GESS using pillars and pulleys (proposed by Cao Xinjiang), gravity based underground energy storage (proposed by Gravity power company in 2011) [6]. In this paper recent developments in gravity based technologies have been discussed in detail.

\section{A. 2. NEED FOR ENERGY STORAGE}

Different means for storing the energy in a readily recoverable form when the supply exceeds the demand to be use at other times is known as "Energy storage" [7]. While dealing with electric grid, aim of operator is always to achieve grid balancing i.e. electric supply should be equal to demand. Mismatch between supply and demand results either in power outage or grid failure or frequency and voltage fluctuations. But as we know Renewable energy resources (RES) are unpredictable in nature and they give variable output so there may be a mismatch between supply and demand for RES based generation system. Figure 2 shows that this problem can be solved by storing excess energy at off-peak hours. Hence, the rapid increase in use of RESnotably wind and solar, has led to a strong initiative to develop energy storage for electricity on a large scale [8]. Electrical Energy storage (EES) allows us to utilize the intermittent and variable energy resources such as solar, wind etc. effectively. EES is also needed for electric vehicles (EV), which is going to be a new normal. For EV, transportable storage is needed as the vehicle must carry its energy supply [7]. If a renewable is used as base-load supplier then it must be able to meet the load demand over many days not only for some hours. In that case EES is also required [8].

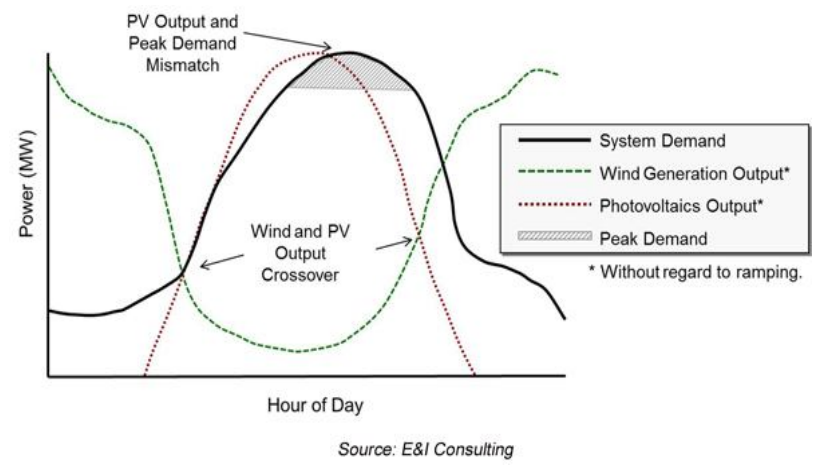

Figure 2: Solar and Wind generation without storage system

As shown in figure 3, during off-peak hours, when supply is greater than demand, the electrical energy can be stored and it can be supplied back when demand is at its peak. Thus, EES reduces the total capacity need of a generation plant. Hence, EES plays three major role- a) lowering the electricity supply cost by storing energy at off-peak rates, b) improves reliability at times of unexpected failures or disasters, and c) maintains and improves power quality (frequency and voltage) [9]. 


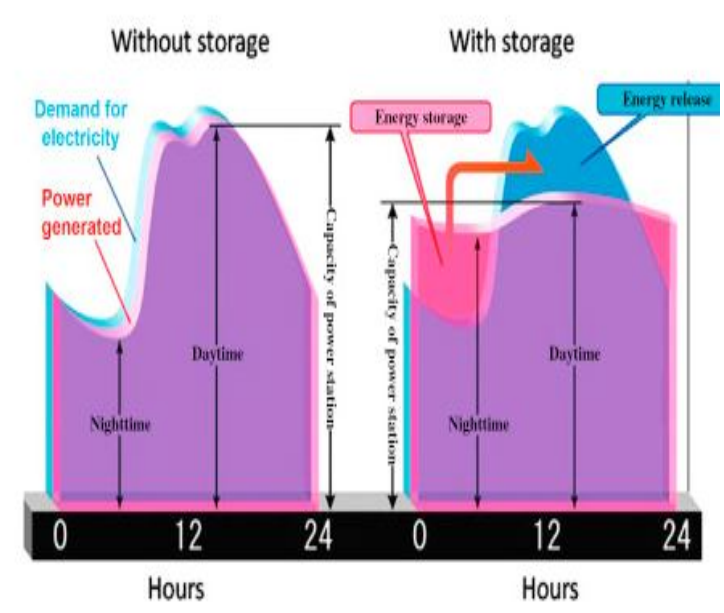

Figure 3: Benefit of energy storage [9].

A notable economical benefit of energy storage is that the utility can store the energy during off-peak hours when electricity price is low and deliver it during peak-hours when electricity prices are generally higher.

\section{Gravity based energy storage technologies:}

Gravity is a powerful force which surrounds us at all the time and can provide a very effective energy storing solutions. The basic concept behind Gravity energy storage (GES) is to store the gravitational potential energy using some hydraulic system. At offpeak hours or when generation is more, then surplus electricity is employed to raise a mass (several tones) which stores potential energy and at peak hours, when demand is high the raised mass is released to generate electricity via generator $[10,11]$. The concept of Gravity Storage was invented by Professor Eduard Heindl in 2010 and has since the company Heindl Energy GmbH continually developing it, which was supported by a team of civil engineering, geological, mining and geophysics specialists [10].

\subsection{Pumped Hydro Storage (PHS) :}

A Pumped Hydro Storage (PHS) may be considered as a gravity battery as it uses the gravitational potential energy. Pumped hydroelectric storage facilities store energy in the form of water. When electricity is in excess, it is used to pump water from a lower elevation reservoir to another reservoir located at higher elevation. During peak demand period water is allowed to flow back through turbines which then rotate the shaft of alternators which in turn produces electricity. Reversible pump- turbine/motor-generator assemblies can act as both pumps and turbines.

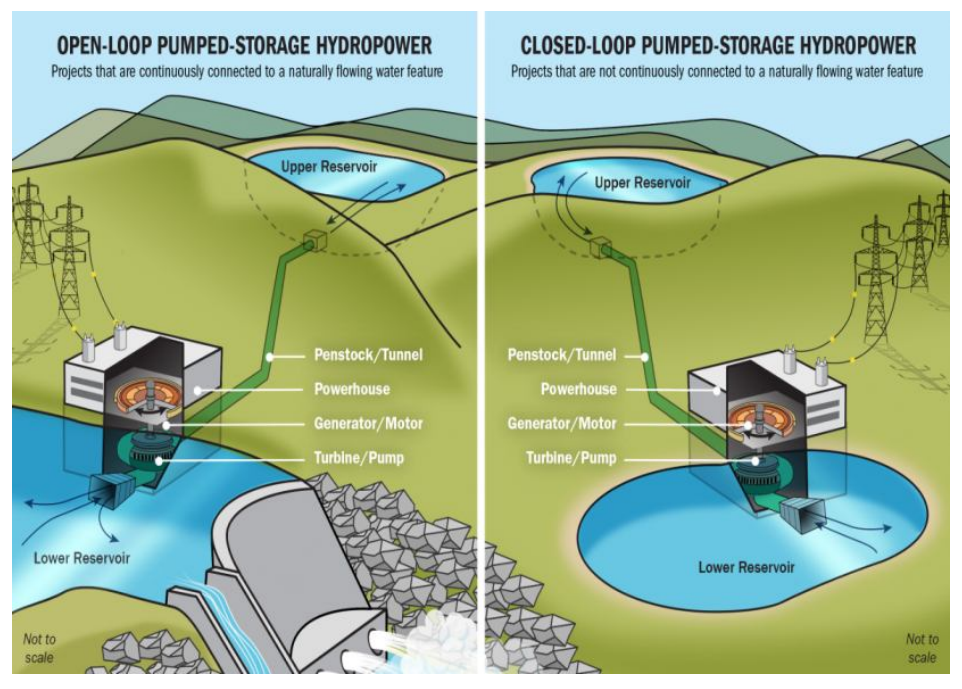

Figure 4: concept of pumped hydro storage (PHS)

As shown in figure 4, PHS can be employed in two different ways either open loop system or closed loop system. PHS is the most successful, economical and widely used storing technique in present time available to electric utilities for load leveling. PHS can also be used to store electrical energy produced by solar and wind. Practically the overall energy recovery efficiency of PHS varies between 70-80\%.

Limitations:However, PHS system suffers from some geographical limitations as there are very few suitable sites where there is water supply at lower level and a reservoir can be built at a higher level. If such location is available then there must be huge availability of water is needed.

These sitting issues related to PHS can be overcome using other gravity based storage system. A generally applied mechanism of gravity based storage at PV generation site is proposed by Gravity Power Company in 2011, which was based on Hydraulic storage technology [6]. 

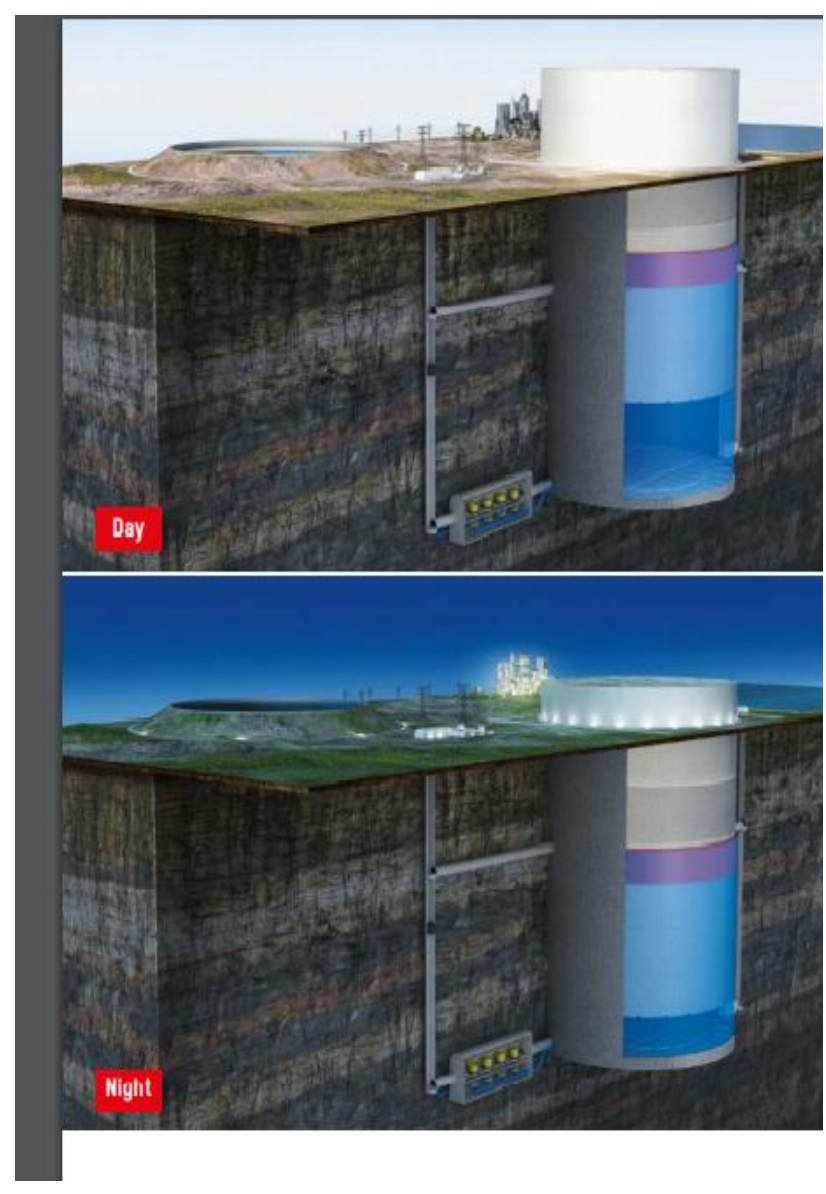

Figure 5: Gravity based energy storage mechanism using hydraulic system [12].

\subsection{Hydraulic storage technology:}

As shown in figure 5, in this technology, a very large rock mass is lifted using water pump based on hydraulic lifting. The mass acquires potential energy due to lifting at off peak hours. During peak hours, the mass is released which put a pressure on beneath water and forces it to discharge back through turbines which produces electricity $[6,12]$.

The storage capacity (E) of this system is given by the density $\rho_{r}$ of the rock and the density $\rho_{w}$ of water, and the gravitational acceleration $\mathrm{g}$.

$$
E=\left(2 \rho_{r}-\frac{3}{2 \rho_{w}}\right) \pi g r^{4}
$$

Two important points here to be discussed are, the storage capacity can be increased 16 times by just doubling the radius of piston (r) as $\left(E \alpha r^{4}\right)$, and construction cost only increases with square of radius $\left(r^{2}\right)$. So effectively relative cost per energy unit decreases proportionally to $1 / r^{2}$.

A data is provided in [10] showing storage capacity for a rock density of $2600 \mathrm{~kg} / \mathrm{m}^{3}$ as provided in Table 1. According to which a radius of $250 \mathrm{~m}$ would already result in a storage capacity of $8 \mathrm{GWh}$, which is comparable to the largest pumped storage power station in Goldisthal, Germany (8.4 GWh).

Table 1: Different values ofstorage capacities for a rock density of $2600 \mathrm{~kg} / \mathrm{m}^{3}$ for various values of radius of piston

\begin{tabular}{|l|l|l|l|l|}
\hline $\begin{array}{l}\text { Usable } \\
\text { storage } \\
\text { capacity } \\
(\mathbf{G W h})\end{array}$ & 1 & 3 & 8 & 80 \\
\hline $\begin{array}{l}\text { Diameter } \\
\left(\boldsymbol{m}^{\mathbf{3}}\right)\end{array}$ & 150 & 200 & 250 & 500 \\
\hline $\begin{array}{l}\text { Volume } \\
\text { of water } \\
(\mathbf{1 0 0 0} \\
\left.\boldsymbol{m}^{\mathbf{3}}\right)\end{array}$ & 1,340 & 2,380 & 5,990 & 38,580 \\
\hline $\begin{array}{l}\text { Pressure } \\
(\mathbf{b a r})\end{array}$ & 41 & 67 & 71 & 105 \\
\hline
\end{tabular}

Advantage:For Goldisthal PHS (of 8.4GWh) have a upper reservior of 12 million cubic meters working water capacity while in above proposed system of $8 \mathrm{GWh}$ only 5.9 million cubic meters water is required. So the system has reduced the water requirement to a great extent. Also it has a round trip efficiency of $75-80 \%$. Another advantage of this system is that the operating life of the system is practically unlimited because its main components are rock mass and tunnel which can be constructed using proven mining and civil engineering technologies and is extremely durable. The other electrical equipments, such as pumps, turbines and generator, can be designed for a service life of 60 years or more, and can then be replaced as required. The capacity of energy storage using this concept can be chosen between 1 and $10 \mathrm{GWh}$, comparable to large Pumped Hydro Storage. 


\subsection{Gravitricity system:}

Figure 6 shows, another gravity based energy storage technique, completely removes the utilization of water to store energy has been developed by a Scottish-based startup Gravtricity. The concept is similar to the previous method of raising and lowering down a heavy mass to store and deliver energy as needed, but it does not use water. The key requirement for this system is a deep hole in the ground in which the heavy mass can be suspended. The Gravitricity system suspends weights of 5005000 tones in a deep shaft by a number of cables and each cable is engaged with a winch, which is capable to lift and hold the weight. The winch system is controlled accurately by the use of electrical drives to keep the weight stable in the hole. Initially the company is using existing abandoned mineshaft. Shaft depths can be ranging from $150 \mathrm{~m}$ to $1500 \mathrm{~m}$. . Modern power electronics is employed for the grid connection to permit the rapid switching between generation and absorption of power. The system can deliver both active aswell as reactive power to stabilize the grid. Main features of Gravtricity technology are:

$>$ It has a 50-year design life and no cycle limit and degradation.

$>$ Response time of the system is less than one second from zero to full power.

$>$ Efficiency of this system is $80-90 \%$.

$>$ The system can be run slowly at low power and fast at high power.

$>$ It is easy to construct near networks and does not require any special topographic location.

$>$ It is cost effective also compared to lithium batteries.

Each unit of this system can be configured to produce between 1 and 200 MW peak power, with a output duration between 15 minutes to 8 hours [11]. The system can be used to store both Solar and Wind power.

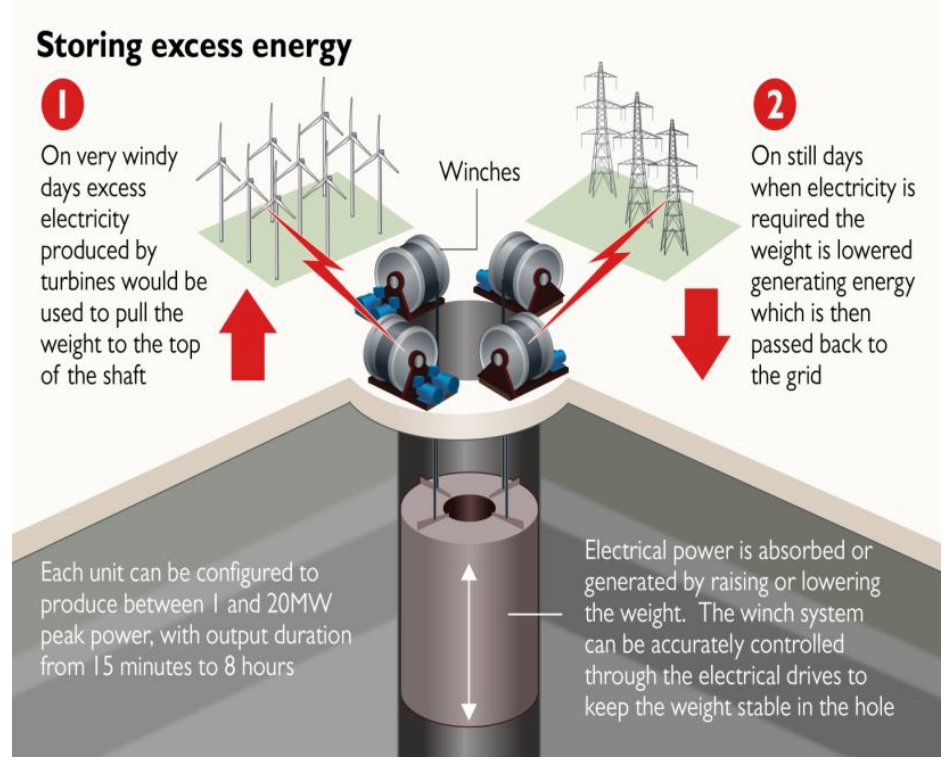

Figure 6: Gravitricity energy storage demonstration [13].

\subsection{Energy Vault company GESS}

As in figure 7, another GESS using large and heavy concrete blocks is developed by Energy Vault company. The system uses a 6-arms crane which sits atop a 33-storey building, raises and lowers down around 5000 concrete blocks weighing 35 tones in total, to store energy. Energy is stored when the bricks are lifted up and supplied back when bricks are returned to the ground. Specially engineered control softwares are used to ensure that bricks are placed at right location each time. The storage system capability ranges between 20-80 MWh and a 4-8 MW of continuous power supply for 8-16 hours. The system has a very fast response and suited for long duration storage. The system can also be used for ancillary services [14].

California based Advanced Rail Energy Storage LLC (ARES) has developed and patented a breakthrough gravitational energy storage system, which uses proven electric railroad technology with modern power electronics to carry its heavy weights up a steep slope, as shown in figure 8 . This innovative technology consists of two large storage yards, which are located at different elevations or must have some gentle slope to use the 


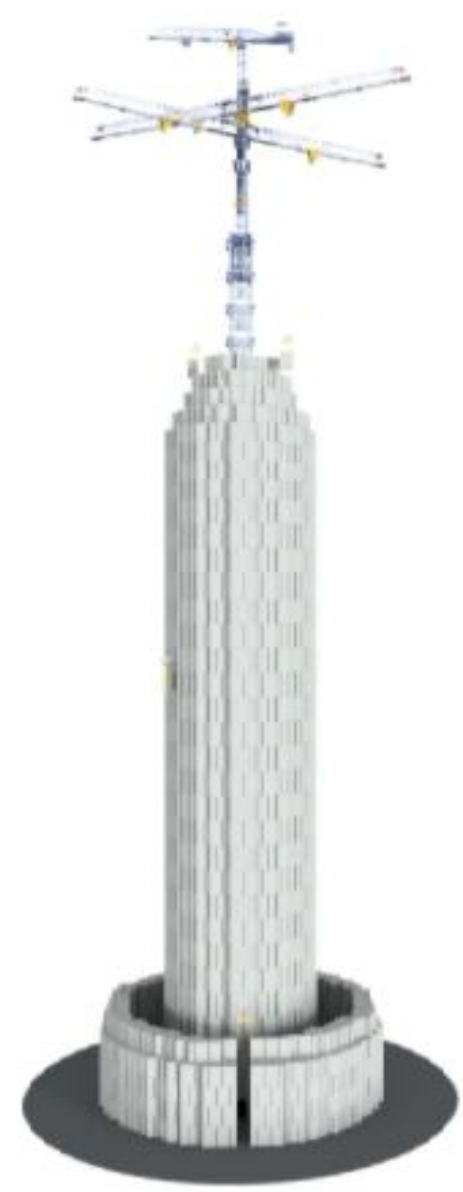

Figure 7: GESS technology developed by EnergyVault [14].

power of gravity. These yards are connected to each other by some railway tracks. Each yard contains many heavy masses (typically heavy concrete weights), which are carried up and relocated by a specially designed locomotive system. This whole system, consisting of locomotive and masses is known as a Shuttle and when it contains an electrical machine, it is called a car. When this car shuttle is raised uphill, the electrical machine works as a motor and it stores energy. And when the car-shuttle descends downhill (in discharging), the machine operates as generator and feed the electricity to grid. The phenomenon is similar to Regenerative braking. A pilot project by ARES of $50 \mathrm{MW}$ in Pahrump, Nevada has a energy storage capacity of $12.5 \mathrm{MWh}$. It has a 9600 US tons of total weight of trains. Practically the ARES system has a efficiency of $78 \%$ $[15,16]$.
A. ARES Cable Winch
B. Heavy Haul Slab Track
C. $140 t$ Mass
D. Loaded Shuttle Delivering Mass
E. Unloaded Shuttle Returning to Pick Up Next Mass

Figure 8: ARES technology demonstration [15].

\section{WORLDWIDE SCENARIO OF GRAVITY BASED ENERGY STORAGE:}

Pumped Hydro Storage (PHS) is the leading storing technique available worldwide, not only in gravity based technologies but among all the technologies available for storing energy like Battery storage, CAES, FES etc. Figure 9 shows worldwide installed data of PHS. It has a round trip efficiency of around $72-75 \%$ [11].

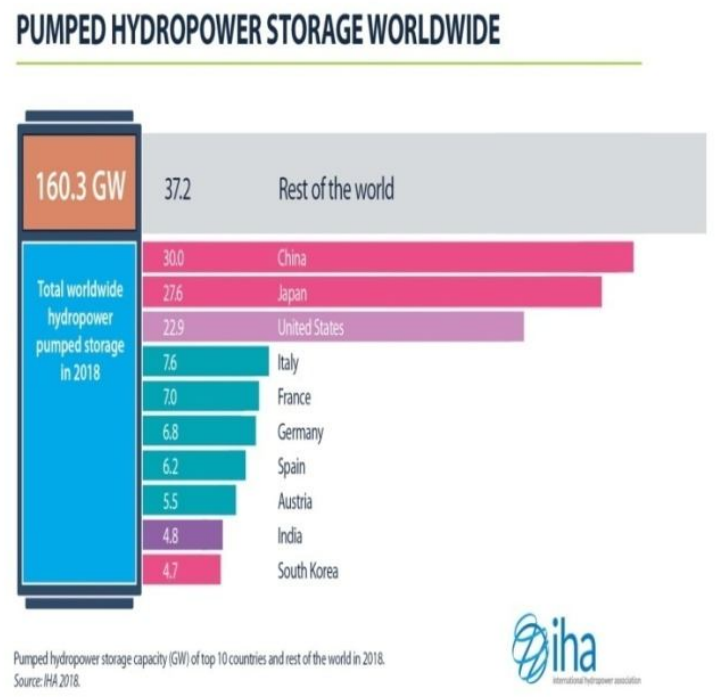

Figure 9: PHS installed capacity worldwide in 2018

In June 2018, the Australian federal government announced that 14 sites had been identified in Tasmania for pumped storage hydro, with the potential of adding $4.8 \mathrm{GW}$ to the national grid. According to the United States Department of Energy 
Ravi Gupta et al., International Journal of Emerging Trends in Engineering Research, 8(9), September 2020, 6406 - 6414

Global Energy Storage Database, in 2020 PHS accounts for around $95 \%$ of all active tracked storage installations worldwide, with a total installed throughput capacity of over $181 \mathrm{GW}$, of which about $29 \mathrm{GW}$ are in the United States . Presently US has the largest capacity PHS in the world of 3003MW. Now China is all set for $40 \mathrm{GW}$ of pumped hydro storage in 2020 .

World's $2^{\text {nd }}$ and $3^{\text {rd }}$ largest capacity PHS power stations are in China of capacity 2448MW and 2400MW respectively. The National Energy Administration of China, says there is already 19.23 GW of pumped hydro storage capacity in China with a further $31.15 \mathrm{GW}$ under construction, including the $\$ 2.78$ billion Fengning project in Hebei province which is set to be the world's largest. Currently there are many projects under construction also in China each of capacity greater than 1000MW. Another emerging country in PHS system is India. India's largest capacity PHS power system is at Sardar Sarovar Dam of capacity 1450MW. In march 2019, Institute for Energy Economics and Financial Analysis (IEEFA), presents a report, stating that India has been formulating plans to become a world leader in PHS. Some $2.6 \mathrm{GW}$ of PHS are already operational with another $3.1 \mathrm{GW}$ under construction. Another 8.9GW PHS system is proposed. India has already set a goal of $175 \mathrm{GW}$ of renewable energy installation by 2022 and storage is the major key issue with renewable. So IEEFA believed that PHS will play a major role as a storage solution $[17,18]$. Some of the other leading countries in PHS technology are Japan, Germany, UK, Taiwan etc.

As it is already discussed in section 3 that due to some limitations of PHS, the world is increasing its effort towards other GESS, which are having a comparatively higher round trip efficiency, lower installation cost, greater durability and almost pollution free. However, there are very few GESS systems that are installed worldwide and most of them are employed as pilot project of small scale storage system, but due to it promising features this system will achieve much consideration in near future for energy storing solution. There are many companies and startups which are currently working on this technology since last 5-10 years and trying to employ this system practically for large power storage of several hundreds of MW. Currently some leading company in this field are Energy Vault;
Heindl Energy; Gravitricity; StratoSolar Inc; ARES, north America.

Scottish startup Gravitricity is set to build a $£ 1$ million demonstration of the technology Edinburgh, UK. It will start the building work on project in October 2020. This is a small scale (250KW) pilot project which will show it's interconnection with grid and speed of response and will help to establish Gravitricity's first full scale 4MW storage capacity, which was planned for 2021 [19]. Another US based company, Gravity Storage Inc, is currently looking for partners to plan and construct a demonstration plant in order to prove the GESS concept's viability.

While on the other hand, Robert piconi, the CEO of Energy Vault has confirmed that Indian power provider TATA power was one of the first firms to show the interest in bringing the GESS in commercial application. In November 2018, Energy Vault had made a deal with Tata Power to deploy a $35 \mathrm{MWh}$ system in that year. This small scale project will have a peak power output of 4MW. Indian government is also interested in the GESS technology. The Ministry of New and Renewable Energy (MNRE) is planning to float a tender to invite companies to set up GESS plants in India. International GESS companies like Energy Vault, Gravitricity and Gravity Storage Inc have already shown interest [20].

Another Company ARES has successfully built and operated a rail-based energy storage project in Tehachapi, California, which demonstrates it's fast response and working as energy storing solution. On March 28, 2016 ARES announced that it got permission to work on its first commercial frequency regulation facility in Clark and Nye counties, Nevada. This 50MW capacity project will encompass 106 acres of public land in Southern Nevada and will work to provide Ancillary services in system.

\section{CONCLUSION}

In this paper, an overview of Gravity based Energy Storage System (GESS) has been presented. GESS is an emerging concept as a solution for storing energy which will help in smooth and more reliable penetration of renewable in electric grid. Various GESS technologies like PHS, ARES, gravity battery 
Ravi Gupta et al., International Journal of Emerging Trends in Engineering Research, 8(9), September 2020, 6406 - 6414

etc. are explained with their various advantages over other storing techniques, and practical applications. Studies show these systems have zero requirements of fossil fuels and do not emit any harmful gas. GESS (excluding PHS), does not have any topographic limitation, does not use any environmentally sensitive materials and can be constructed easily. However, a huge research and development work is needed to implement the system practically and to make it compatible as a better energy storing technique. Study shows that PHS is the leading storage technique while other GESS technologies are still in their initial phase and most of them are employed as pilot project in different parts of world. But in future, it will definitely play a major role in providing a highly efficient, durable, pollution free\& reliable storing system which can be used as both, either to supply power at peak demands or to provide ancillary services in the electric grid.

\section{REFERENCES}

1. "Solar PV System For Electric Traction Application With Battery Backup". 2019. International Journal Of Emerging Technologies In Engineering Research (IJETER) 7 (1).

2. .Prashantkumarpathak, and Atma Ram Gupta. 2018. "Battery Energy Storage System". International Conference On "Computational Intelligence And Communication Technology" (CICT 2018).

3. Said OuldAmrouche, DjamilaRekioua, and ToufikRekioua. 2016. "Overview Of Energy Storage In Renewable Energy Systems". International Journal Of Hydrogen Energy 41 (45): 20914-20927. doi:10.1016/j.ijhydene.2016.06.243.

4. International Renewable Energy Agency. 2020. "Renewable Capacity Highlights 31 March 2020". https://www.irena.org//media/Files/IRENA/ Agency/Publication/2020/Mar/IRENA_RE_ Capacity_Highlights_2020.pdf?la=en\&hash =B6BDF8C3306D271327729B9F9C9AF5F 1274FE30B\#: :text=Renewable\%20generati on $\% 20$ capacity $\% 20$ increased $\% 20$ by,by $\% 20 \mathrm{j}$ ust $\% 20$ under $\% 20700 \% 20 \mathrm{MW}$.

5. "Hybrid Power Generation Using Solar, Wind And Micro Hydel". 2016. International
Journal Of Emerging Technologies In Engineering Research (IJETER) 8 (4).

6. Yangyang, Chen, Hui Hou, Tao Xu, Xixiu Wu, Peng Liu, and Huan Wang. 2019. "A New Gravity Energy Storage Operation Mode To Accommodate Renewable Energy". IEEE.

7. Khan, B.H. 2013. Non-Conventional Energy Resources. 2nd ed. NEW DELHI: McGraw Hill Education (India) Private Limited.

8. "Electricity And Energy Storage - World Nuclear Association". 2020. WorldNuclear.Org. $\quad$ https://www.worldnuclear.org/information-library/current-andfuture-generation/electricity-and-energystorage.aspx.

9. Jana, Aniruddha, and Ajit K. Roy. 2019. "Electrical Energy Storage - An Overview | Sciencedirect Topics". Sciencedirect.Com. https://www.sciencedirect.com/topics/materi als-

science/electricalenergystorage\#: :text=Elec trical\%20energy\%20storage $\% 20$ (EES)\%20p lays, quality $\% 20$ (frequency $\% 20$ and $\% 20$ volta ge).

10. "Gravitricity". 2020. Gravitricity.Com. https://www.gravitricity.com/\#fast-long-lifeenergy-storage.

11. Ruoso, Ana Cristina, Nattan Roberto Caetano, and Luiz Alberto Oliveira Rocha. 2019. "Storage Gravitational Energy For Small Scale Industrial And Residential Applications". Inventions 4 (4): 64. doi:10.3390/inventions4040064.

12. "Gravity Storage - A New Technology For Large Scale Energy Storage". 2020. Gravity Storage. https://heindl-energy.com/.

13. Andrews, Roger. 2018. "Short-Term Energy Storage With "Gravitricity" - Iron Versus Ion". Energy Matters. http://euanmearns.com/short-term-energystorage-with-gravitricity-iron-versus-ion/.

14. Husseini, Talal. 2019. "Tower Of Power: Gravity-Based Storage Evolves Beyond Pumped Hydro". Verdict Media Limited. https://www.power-technology.com/ features/gravity-based-storage/.

15. Advanced Rail Energy Storage. 2016. Ebook. Tehachapi, California. https://s3.amazonaws.com/siteninja/multiten 
Ravi Gupta et al., International Journal of Emerging Trends in Engineering Research, 8(9), September 2020, 6406 - 6414

ant/assets/21125/files/original/All_About_A RES_-_070616.pdf.

16. Moazzami, Majid, Jalal Moradi, Hossein Shahinzadeh, Gevork B. Gharehpetian, and Hasan Mogoei. 2018. "Optimal Economic Operation Of Microgrids Integrating Wind Farms And Advanced Rail Energy Storage System". INTERNATIONAL JOURNAL Of RENEWABLE ENERGY RESEARCH 8 (2).

17. Buckley, Tim. 2019. "How India Is Set To Become A Leader In Pumped Hydro Storage - Opinion By Tim Buckley | ET Energyworld". Etenergyworld.Com. https://energy.economictimes.indiatimes.co $\mathrm{m} /$ energy-speak/how-india-is-set-tobecome-a-leader-in-pumped-hydrostorage/3484.

18. Institute for Energy Economics and Financial Analysis (IEEFA). 2019. "Pumped Hydro Storage In India."
19. "\&\#163;1M Gravity Energy Storage Pilot System To Be Built In UK". 2020. Hazardexonthenet.Net.

http://www.hazardexonthenet.net/article/178 416/-1m-gravity-energy-storage-pilotsystem-to-be-built-in-

UK.aspx\#: :text=Gravitricity $\% 2 \mathrm{C} \% 20$ the $\%$ 20team $\% 20$ behind $\% 20$ a,rental $\% 20$ agreeme nt $\% 20$ in $\% 20$ Edinburgh $\% 2$ C\%20UK.

20. Kumar, Ankush. 2019. "Government To Float Tender For Gravity Storage; Foreign Firms Keen On Prospects". Economic Times, , 2019.

https://energy.economictimes.indiatimes.co $\mathrm{m} /$ news/renewable/government-to-floattender-for-gravity-storage-foreign-firmskeen-on-prospects/69954470. 